\title{
DESCRIÇÃO ANATÔMICA DA MADEIRA DE MYRCIA BOMBYCINA (O. BERG) NIEDENZU (MYRTACEAE) ${ }^{1}$
}

\author{
JOSÉ NEWTON CARDOSO MARCHIORI ${ }^{2}$ SIDINEI RODRIGUES DOS SANTOS ${ }^{3}$
}

\section{RESUMO}

É fornecida a descrição microscópica da madeira de Myrcia bombycina (O. Berg) Niedenzu, a partir de material procedente do Rio Grande do Sul. Os principais caracteres anatômicos observados coincidem com referências da literatura para a família Myrtaceae. Com relação ao gênero Myrcia e às espécies nativas no Estado, há que se ressaltar a presença de espessamentos espiralados nos vasos, de abundante conteúdo nos raios, de pontoações intervasculares de diâmetro médio, bem como pequenas diferenças na frequiência de poros, na altura de séries parenquimáticas e de raios.

Palavras-chave: Myrcia bombycina, anatomia da madeira, Myrtaceae.

\section{ABSTRACT}

[Wood anatomy of Myrcia bombycina (O. Berg) Niedenzu (Myrtaceae)].

The microscopic wood description of Myrcia bombycina (O. Berg) Niedenzu is furnished, based on materials from Rio Grande do Sul state, Brazil. Most of the anatomical features are according to the literature on family Myrtaceae. With regard to genus Myrcia and other native species in Rio Grande do Sul state, it must be emphasized the presence of spiral thickenings in vessel walls, the abundant organic inclusions in ray cells, the medium-size intervessel pits, as well as some differences on pore frequency, and the height of rays and wood parenchyma.

Key words: Myrcia bombycina, wood anatomy, Myrtaceae.

\section{INTRODUÇÃO}

Myrcia bombycina é arbusto ou árvore pequena (até 6 metros de altura), de córtex rugoso e folhas oblongas ou oblongo-lanceoladas, nitidamente discolores e de aspecto sedoso na face inferior, devido à abundância de tricomas. As flores, brancas e numerosas (Marchiori \& Sobral, 1997), reúnem-se em inflorescências axilares ou terminais (Sobral, 2003).

Popularmente conhecida como guamirim, a espécie é nativa na Argentina, Paraguai e

1 Os autores agradecem a Geremias Damian Nunes, pelo auxílio nas medições anatômicas. Recebido em 20/4/ 2009 e aceito para publicação em 20/6/2009.

2 Engenheiro Florestal, Dr., bolsista de Produtividade em Pesquisa do CNPq, Professor Titular do Departamento de Ciências Florestais, Universidade Federal de Santa Maria, Santa Maria, RS, Brasil.Balduinia@mail.ufsm.br

3 Biólogo, bolsista do $\mathrm{CNPq}$ - Brasil, doutorando do Programa de Pós-Graduação em Engenharia Florestal, Departamento de Ciências Florestais, Universidade Federal de Santa Maria, CEP 97105-900, Santa Maria, RS, Brasil.sthurt.bio@gmail.com
Brasil, de Goiás até o Rio Grande do Sul (Legrand \& Klein, 1969). Neste Estado, pode ser encontrada em matas com Araucária do Planalto, nos Campos de Cima da Serra, na Floresta Estacional do Alto Uruguai e, com menos frequência, na Depressão Central (Sobral, 2003), ocupando, principalmente, a orla de matas e capões. A madeira, usada localmente como lenha ou para fabricação de pequenas peças (Marchiori \& Sobral, 1997), é ainda desconhecida sob o ponto de vista anatômico, à semelhança da maioria das espécies do gênero, nativas no Rio Grande do Sul.

\section{REVISÃO DE LITERATURA}

São muito escassas as referências sobre a estrutura anatômica da madeira no gênero Myrcia. Para Myrcia anceps O. Berg, M. lineata (O. Berg) Barroso \& Peixoto e M. rostrata DC., Barros et al. (2001) relacionam: porosidade difusa; poros exclusivamente solitários, de seção circular a oval; placas de perfuração sim- 
ples; pontoações raio-vasculares de aréolas distintas; fibras com pontoações areoladas, de comprimento médio e paredes finas a espessas; parênquima apotraqueal difuso, difuso-em-agregados e paratraqueal escasso; presença de traqueídeos; e raios com menos de 5 células de largura, heterogêneos, com células procumbentes, na porção central, e células eretas e quadradas, nas margens, por vezes de paredes disjuntas.

Para o conjunto do gênero, Metcalfe \& Chalk (1972) destacam: poros de diâmetro inferior a $50 \mu \mathrm{m}$ até maiores do que $100 \mu \mathrm{m}$, com frequiência de 5-20 (até 40-100) poros $/ \mathrm{mm}^{2}$; cristais em câmaras no parênquima axial, ocasionalmente mais largas do que as células normais da série; e raios tipicamente heterogêneos, por vezes com mais de 10 fileiras marginais de células eretas, menos comumente homogêneos.

Para o conjunto das Mirtáceas, Record \& Hess (1949) relacionam: placas de perfuração simples (com exceção de Myrceugenia apiculata); pontoações intervasculares ornamentadas; parênquima apotraqueal; fibras com pontoações areoladas; traqueídeos vasicêntricos; raios nitidamente heterogêneos; e ausência de espessamentos espiralados em vasos (exceto em Myrceugenia fernesiana e Myrceugenia schulzii). Segundo os mesmos autores, as madeiras de Myrcia assemelham-se, estruturalmente, às de Eugenia spp.

\section{MATERIAL E MÉTODOS}

Coletado no Parque Estadual de Nonoai (RS), o material em estudo corresponde a uma amostra de madeira e respectivo material botânico, conservados na Xiloteca e Herbário do Departamento de Ciências Florestais (HDCF) da Universidade Federal de Santa Maria, sob o número 2814.

Para a descrição da madeira, foram preparadas lâminas de cortes anatômicos e de macerado. Do material lenhoso, foram extraídos três corpos de prova $(3 \times 3 \times 3 \mathrm{~cm})$ da parte mais externa do lenho, próxima ao câmbio, orientados para obtenção de cortes nos planos transversal, longitudinal radial e longitudinal tangencial. Um outro bloco foi também retirado, com vistas à maceração.

No preparo das lâminas de cortes anatômicos seguiu-se a técnica padrão no Laboratório de Anatomia da Madeira da Universidade Federal do Paraná: as amostras de madeira foram amolecidas por fervura em água e seccionadas em micrótomo de deslizamento, regulado para a obtenção de cortes com espessura nominal de $20 \mu \mathrm{m}$. Os cortes foram tingidos com acridinavermelha, crisoidina e azul-de-astra (Dujardin, 1964), desidratados em série alcoólica-ascendente $(30 \%, 50 \%, 70 \%, 95 \%$ e duas vezes álcool absoluto), diafanizados em xilol e montados em lâminas permanentes, com "Entellan".

Para as lâminas de macerado, usou-se o método de Jeffrey (Burger \& Richter, 1991) e coloração da pasta com safranina $1 \%$; a montagem de lâminas seguiu o anteriormente descrito, com a diferença de que as três primeiras etapas foram desenvolvidas sobre papel de filtro.

A descrição microscópica da madeira baseou-se nas recomendações do IAWA Committee (1989). No caso da percentagem dos tecidos, foram realizadas 600 determinações ao acaso, com o uso de contador de laboratório, conforme proposto por Marchiori (1980). A frequiência de poros $/ \mathrm{mm}^{2}$ foi obtida de forma indireta, a partir de um quadrado de área conhecida, superposto a fotomicrografias de seção transversal da madeira. As medições foram realizadas em microscópio Carl Zeiss, com ocular de escala graduada, no Laboratório de Anatomia da Madeira da Universidade Federal de Santa Maria. Nas características quantitativas, os números entre parênteses equivalem aos valores mínimos e máximos observados. O valor que acompanha a média é o desvio padrão. As fotomicrografias foram tomadas em aparelho Olympus cx40, equipado com câmera digital Olympus Camedia c3000. 


\section{DESCRIÇÃO ANATÔMICA}

Madeira de porosidade difusa. Anéis de crescimento distintos, delimitados por estreita camada de fibras radialmente achatadas e de paredes fortemente lignificadas (Figura 1A).

Vasos numerosos $(34 \pm 5,6(25-37)$ poros / $\mathrm{mm}^{2}$ ), ocupando $14,5 \pm 3,7 \%$ do volume da madeira. Poros exclusivamente solitários, de seção circular a oval, pequenos $(58,5 \pm 13,8$ $(31,2-88,7) \mu \mathrm{m})$ e de paredes espessas $(3,0 \pm$ $0,7(1,9-5,0) \mu \mathrm{m})$, sem padrão definido de organização (Figura 1A,B). Elementos vasculares de comprimento médio $(460,8 \pm 80,5$ (300 630) $\mu \mathrm{m}$ ). Placas de perfuração simples, oblíquas, por vezes transversais; apêndices, geralmente em ambas as extremidades (Figura 1D). Espessamentos espiralados tênues e largos, observados em parte dos vasos. Pontoações intervasculares de diâmetro médio, circulares $(7,5 \pm 0,98(6,2-9,3) \mu \mathrm{m})$ e alternas, com abertura em fenda inclusa, ornamentada (Figura 1G). Pontoações raio-vasculares de aréolas distintas, semelhantes às intervasculares (ocasionalmente ovais), porém menores $(3,7 \pm 0,53(3,1-4,1)$ $\mu \mathrm{m})$ e restritas às margens de raios.

Parênquima axial representando $25,7 \pm 2,3$ $\%$ do volume da madeira, contrastante com as fibras pela abundância de conteúdos; em arranjo apotraqueal difuso, difuso-em-agregados e paratraqueal escasso (Figura 1A,B). Séries parenquimáticas, geralmente com 4 (2 - 5) células, e $432 \pm 69,1(257,5-517,5) \mu \mathrm{m}$ de altura (Figura 1F).

Raios muito numerosos $(23 \pm 2,6(23-29)$ raios / $\mathrm{mm}$ ), ocupando $25,7 \pm 2,3 \%$ do volume da madeira; heterocelulares, reúnem células procumbentes, na parte multisseriada, e $1-8$ (mais comumente 2-5) fileiras marginais de células quadradas e principalmente eretas, raro procumbentes mais altas do que as do corpo central (Figura 1C,D,F). Raios estreitos, com 1 - 4 células de largura (Figura 1E,F). Raios multisseriados, com 9 - 21, mais comumente 9 15 células de altura, medindo 320,4 \pm 89,3 (200 - 510) $\mu \mathrm{m}$. As margens unisseriadas são de ta- manho variável com relação ao corpo. Raios unisseriados, predominantes, com $1-12$, mais frequentemente 1 - 7 células e 222,8 \pm 104,3 $(60-500) \mu \mathrm{m}$ de altura. Raios axialmente fusionados, escassos. Conteúdos, abundantes em células radiais, à semelhança do parênquima axial (Figura 1C,D). Células radiais de paredes disjuntas, presentes. Raios agregados, células envolventes e células perfuradas, ausentes.

Tecido fibroso representando $39,5 \pm 4,9 \%$ do volume da madeira. Fibras com pontoações distintamente areoladas e aberturas cruzadas, nas faces radiais e tangenciais da parede. Fibras curtas $(893,2 \pm 115,2(730-1110) \mu \mathrm{m})$, com 15,6 $\pm 1,8(12,5-20) \mu \mathrm{m}$ de largura e de paredes finas até espessas $(3,4 \pm 0,7(2,5-4,4)$ $\mu \mathrm{m})$ (Figura 1B). Fibras septadas, fibras gelatinosas e espessamentos espiralados, ausentes. Traqueídeos vasicêntricos, presentes.

Demais caracteres: Variantes cambiais, tubos laticíferos e taniníferos, canais intercelulares, células oleíferas ou mucilaginosas, estratificação e cristais, ausentes. Máculas medulares presentes.

\section{ANÁLISE DA ESTRUTURA ANATÔMICA}

Myrcia bomycina reúne características anatômicas comumente atribuídas a Mirtáceas, por Record \& Hess (1949), Metcalfe \& Chalk (1972) e Dias-Leme et al. (1995), entre outros. É o caso da porosidade difusa, de poros solitários e pequenos, de elementos vasculares de comprimento médio, de placas de perfuração simples, de pontoações intervasculares alternas e ornamentadas, de parênquima apotraqueal difuso e difuso-em-agregados, de fibras com pontoações areoladas, de raios heterocelulares e de traqueídeos vasicêntricos. Este conjunto de caracteres é compartilhado pela maioria das espécies sul-rio-grandenses estudadas por Marchiori (1984a,b,c; 1987a,b; 1988; 1997; 1998; 2008), com exceção de Myrceugenia myrtoides (Marchiori, 1987a).

Embora pouco evidentes, foram observados espessamentos espiralados nos vasos de Myrcia 

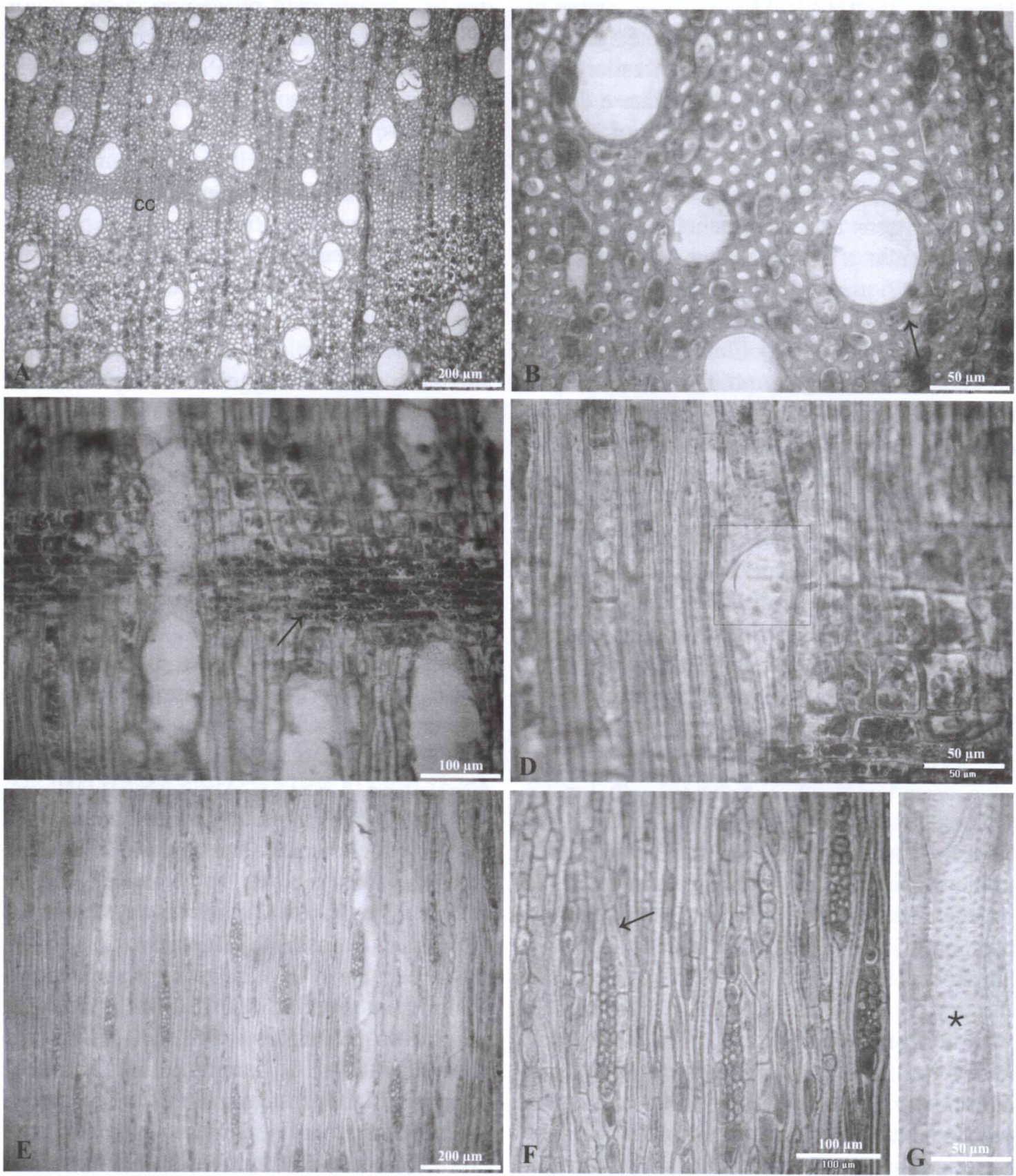

FIGURA 1 - Fotomicrografias da madeira de Myrcia bombycina. A - Seção transversal, mostrando limite de anel de crescimento (cc), porosidade difusa, poros exclusivamente solitários e parênquima apotraqueal. B - Mesma seção, em maior aumento, com destaque para fibras de paredes finas a espessas, poros de forma circular a oval e parênquima apotraqueal difuso e paratraqueal escasso (seta). C - Aspecto geral de raio heterogêneo com abundantes conteúdos, formado por células procumbentes, no corpo, e margens de células predominantemente eretas, em seção longitudinal radial. D - Detalhe da seção radial, mostrando placa de perfuração simples. E - Aspecto geral da seção longitudinal tangencial, com raios uni e multisseriados. F - Mesma seção, em maior aumento, salientando parênquima seriado (seta) e raios heterogêneos. $\mathrm{G}$ - Detalhe de vaso com pontoado intervascular alterno (estrela), em vista tangencial. 
bombycina. A presença deste aspecto anatômico, embora restrito a menor número de espécies na família, não constitui novidade para $o$ gênero em questão. Schmid \& Baas (1984), em estudo do caráter em Myrtaceae, anotaram sua ocorrência em Myrcia, além de outros sete gêneros. Barros et al. (2001), por sua vez, não referem espessamentos espiralados para as madeiras nativas de Myrcia, sugerindo que o mesmo pode servir para separação de espécies.

No material em estudo, cabe salientar a presença de abundante conteúdo, tanto nos raios como no parênquima axial, aspecto que pode ser útil para a distinção com outras espécies do gênero, caso das relacionadas por Barros et al. (2001), desprovidas de tais inclusões na madeira. Este caráter, aliás, é relativamente freqüente em Mirtáceas nativas no Estado, tendo sido atribuído ao tecido radial de pelo menos outras três espécies (Marchiori, 1987a; 1997; 1998).

Com relação ao referido por Barros et al. (2001) para três espécies de Myrcia, há que se ressaltar, ainda, as diferenças no tocante a características quantitativas, tais como: frequência e diâmetro de poros; comprimento de elementos vasculares; diâmetro e comprimento de fibras; altura das séries de parênquima axial; e altura e freqüência de raios. Comparada a outras espécies nativas no Estado, as principais diferenças residem na frequência de poros (34/ $\left.\mathrm{mm}^{2}\right)$ e na altura das séries de parênquima (2-5 células), aspectos que mostraram-se notavelmente inferiores aos valores referidos $\left(>50 / \mathrm{mm}^{2}\right.$ e 4-8 células, respectivamente), bem como na altura dos raios em $\mu \mathrm{m}$, aspecto sabidamente variável entre espécies. Além disso, chama atenção a presença de pontoações intervasculares de diâmetro médio $(6-9 \mu \mathrm{m})$, caráter de ocorrência mais restrita na família (Record \& Hess, 1949; Metcalfe \& Chalk, 1972; Vliet \& Baas, 1984). Convém salientar, todavia, que o uso de valores quantitativos é de valor secundário para fins taxonômicos, mas que, em Myrtaceae, a utilização dos mesmos torna-se, por vezes, ne- cessária, devido à grande homogeneidade estrutural das madeiras (Marchiori, 1984a).

No material em estudo não foram observados cristais, diferentemente de outras espécies do gênero (Metcalfe \& Chalk, 1972; Dias-Leme et al., 1995), caso de Myrcia lineata, nativa no Rio de Janeiro (Barros et al., 2001).

\section{REFERÊNCIAS BIBLIOGRÁFICAS}

BARROS, C.F., CALLADO, C.H., MARCON, M.L., COSTA, C.G., CUNHA, M., LIMA, H.R., MARQUETE, O. Madeiras da mata atlântica. Anatomia do lenho de espécies ocorrentes nos remanescentes florestais do estado do Rio de Janeiro. Rio de Janeiro: Instituto de Pesquisas Jardim Botânico do Rio de Janeiro, 2001. 94p.

BURGER, L.M., RICHTER, H.G. Anatomia da Madeira. São Paulo: Ed. Nobel, 1991. 154 p.

DIAS-LEME, C.L., GASSON, P., LUGHADA, E.N . Wood anatomy of four Myrtaceae genera in the subtribe Myciinae from South America. IAWA Bulletin, n. 16, p. 87-95, 1995.

DUJARDIN, E. P. Eine neue Holz-Zellulosenfaerbung. Mikrokosmos, n. 53, p.94, 1964.

IAWA COMMITTEE. IAWA list of microscopic features for hardwood identification. IAWA Bulletin, v.10, n. 3, p. 218-359, 1989.

LEGRAND, D., KLEIN, R.M. Mirtáceas. Flora llustrada Catarinense. Itajaí: Herbário Barbosa Rodrigues, 1969. p. 217-330.

MARCHIORI, J.N.C. Estudo anatômico do xilema secundário de algumas espécies dos gêneros Acacia e Mimosa, nativas no Estado do Rio Grande do Sul. 1980. 186f. Dissertação (Mestrado em Engenharia Florestal) - Universidade Federal do Paraná, Curitiba.

MARCHIORI, J.N.C. Anatomia da madeira de Eugenia involucrata DC. (Myrtaceae). Ciência e Natura, Santa Maria, v. 6, p. 127-136, 1984a.

MARCHIORI, J.N.C. Anatomia descritiva do lenho de Feijoa sellowiana Berg. Ciência e Natura, Santa Maria, v. 6, p. 117-125, 1984b.

MARCHIORI, J.N.C. Anatomia descritiva da madeira do murtilho, Myrrhinium loranthoides (Hook. et Arn.) Burret (Myrtaceae). Revista Centro de Ciências Rurais, Santa Maria, v. 14, n. 1, p. 4350, 1984c. 
MARCHIORI, J.N.C. Anatomia descritiva da madeira de Myrceugenia myrtoides Berg. Ciência e Natura, Santa Maria, v. 9, p. 113-120, 1987a.

MARCHIORI, J.N.C. Estudo anatômico da madeira de Myrciaria tenella (DC.) Berg. Ciência e Natura, Santa Maria, v. 9, p. 87-95, 1987 b.

MARCHIORI, J.N.C. Estudo anatômico da madeira de Myrceugenia glaucescens (Camb.) Legr. et Kaus. Ciência e Natura, Santa Maria, v. 10, p. 105-113, 1988.

MARCHIORI, J.N.C. Estudo anatômico da madeira de sete-capotes, Campomanesia guazumaefolia (Camb.) Berg. (Myrtaceae). Ciência Rural, Santa Maria, v. 28, n. 1, p. 47-51, 1998.

MARCHIORI, J.N.C, BRUM, E.T. Anatomia da madeira do guamirim-facho, Calyptranthes concinna DC. (Myrtaceae). Ciência Rural, Santa Maria, v. 27, n. 2, p. 217-222, 1997.

MARCHIORI, J.N.C., DENARDI, L., FERREIRA, M.R. Anatomia da madeira de Myrcianthes gigantea (Legr.) Legr. Balduinia, Santa Maria, n. 12, p. 27-31, 2008.
MARCHIORI, J.N.C., SOBRAL, M. Dendrologia das Angiospermas: Myrtales. Santa Maria: Editora UFSM, 1997. 304 p.

METCALFE, C.R., CHALK, L. Anatomy of the Dicotyledons. Oxford: Clarendon Press, 1972. 1500p.

RECORD, S.J., HESS R.W. Timbers of the New World. New Haven: Yale University Press, 1949. 640p.

SCHMID, R., BAAS, P. The occurrence of scalariform perforation plates and helical thickenings in wood of Myrtaceae. IAWA Bulletin, v. 5, n. 3, p. 197-215, 1984.

SOBRAL, M. A família Myrtaceae no Rio Grande do Sul. São Leopoldo: Editora Unisinos, 2003. p. 64-65.

VLIET, G.J.C. VAN, BAAS, P. Wood anatomy and classification of the Myrtales. Annals of the Missouri Botanical Garden, n. 71, p. 783-800, 1984. 